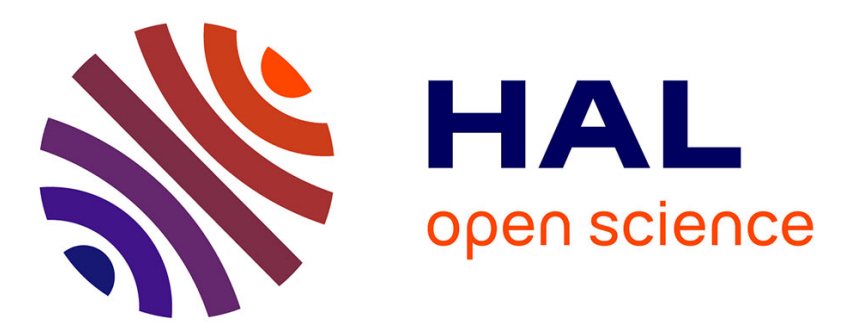

\title{
Serum cytokines associated with behavior: A cross-sectional study in 5-year-old children
}

Susana Barbosa, Olfa Khalfallah, Anne Forhan, Cédric Galera, Barbara

Heude, Nicolas Glaichenhaus, Laetitia Davidovic

\section{- To cite this version:}

Susana Barbosa, Olfa Khalfallah, Anne Forhan, Cédric Galera, Barbara Heude, et al.. Serum cytokines associated with behavior: A cross-sectional study in 5-year-old children. Brain, Behavior, and Immunity, 2020, 87, pp.377 - 387. 10.1016/j.bbi.2020.01.005 . hal-03006169

\section{HAL Id: hal-03006169 \\ https://hal.science/hal-03006169}

Submitted on 14 Dec 2020

HAL is a multi-disciplinary open access archive for the deposit and dissemination of scientific research documents, whether they are published or not. The documents may come from teaching and research institutions in France or abroad, or from public or private research centers.
L'archive ouverte pluridisciplinaire HAL, est destinée au dépôt et à la diffusion de documents scientifiques de niveau recherche, publiés ou non, émanant des établissements d'enseignement et de recherche français ou étrangers, des laboratoires publics ou privés. 
archives-ouvertes

\section{Serum cytokines associated with behavior: A cross-sectional study in 5-year-old children}

Susana Barbosa, Olfa Khalfallah, Anne Forhan, Cédric Galera, Barbara

Heude, Nicolas Glaichenhaus, Laetitia Davidovic

\section{To cite this version:}

Susana Barbosa, Olfa Khalfallah, Anne Forhan, Cédric Galera, Barbara Heude, et al.. Serum cytokines associated with behavior: A cross-sectional study in 5-year-old children. Brain, Behavior, and Immunity, Elsevier, 2020, 87, pp.377 - 387. 10.1016/j.bbi.2020.01.005 . hal-03006169

\section{HAL Id: hal-03006169 \\ https://hal.archives-ouvertes.fr/hal-03006169}

Submitted on 14 Dec 2020

HAL is a multi-disciplinary open access archive for the deposit and dissemination of scientific research documents, whether they are published or not. The documents may come from teaching and research institutions in France or abroad, or from public or private research centers.
L'archive ouverte pluridisciplinaire HAL, est destinée au dépôt et à la diffusion de documents scientifiques de niveau recherche, publiés ou non, émanant des établissements d'enseignement et de recherche français ou étrangers, des laboratoires publics ou privés. 


\title{
Serum cytokines associated with behavior: A cross-sectional study in 5-year- old children
}

\author{
Susana Barbosa ${ }^{\mathrm{a}, 1}$, Olfa Khalfallah ${ }^{\mathrm{a}, 1}$, Anne Forhan ${ }^{\mathrm{b}}$, Cédric Galera ${ }^{\mathrm{c}}$, Barbara Heude ${ }^{\mathrm{b}}$, \\ Nicolas Glaichenhaus ${ }^{a}$, Laetitia Davidovic ${ }^{\mathrm{a}, *}$ \\ ${ }^{a}$ Université Côte d'Azur, Centre National de la Recherche Scientifique, Institut de Pharmacologie Moléculaire et Cellulaire, Valbonne, France \\ ${ }^{\mathrm{b}}$ Université de Paris, Institut National de la Santé et de la Recherche Médicale, Institut National de la Recherche Agronomique, Centre de Recherche en Épidémiologie et \\ Statistiques, Paris, France \\ ${ }^{\mathrm{c}}$ University Bordeaux Segalen, Charles Perrens Hospital, Child and Adolescent Psychiatry Department, Bordeaux, France
}

\section{A R T I C L E I N F O}

\section{Keywords:}

Behavior

Emotion

Children

Cytokines

Mother-child cohort

Penalized regression

\begin{abstract}
A B S T R A C T
Nearly $10 \%$ of 5-year-old children experience social, emotional or behavioral problems and are at increased risk of developing mental disorders later in life. While animal and human studies have demonstrated that cytokines can regulate brain functions, it is unclear whether individual cytokines are associated with specific behavioral dimensions in population-based pediatric samples. Here, we used data and biological samples from 786 motherchild pairs participating to the French national mother-child cohort EDEN. At the age of 5, children were assessed for behavioral difficulties using the Strengths and Difficulties Questionnaire (SDQ) and had their serum collected. Serum samples were analyzed for levels of well-characterized effector or regulatory cytokines. We then used a penalized logistic regression method (Elastic Net), to investigate associations between serum levels of cytokines and each of the five SDQ-assessed behavioral dimensions after adjustment for relevant covariates and confounders, including psychosocial variables. We found that interleukin (IL)-6, IL-7, and IL-15 were associated with increased odds of problems in prosocial behavior, emotions, and peer relationships, respectively. In contrast, eight cytokines were associated with decreased odds of problems in one dimension: IL-8, IL-10, and IL-17A with emotional problems, Tumor Necrosis Factor (TNF)- $\alpha$ with conduct problems, C-C motif chemokine Ligand (CCL)2 with hyperactivity/inattention, C-X-C motif chemokine Ligand (CXCL)10 with peer problems, and CCL3 and IL-16 with abnormal prosocial behavior. Without implying causation, these associations support the notion that cytokines regulate brain functions and behavior and provide a rationale for launching longitudinal studies.
\end{abstract}

\section{Introduction}

Nearly $10 \%$ of 5 -year-old children present behavioral problems and are at increased risk of developing mental disorders later in life (Egger and Angold, 2006; Ogundele, 2018). Complex interactions between genetic as well as pre- and post-natal environmental factors are thought to determine the development of conduct problems, hyperactivity/inattention, social and emotional disturbances in children (Abbott et al., 2018). For example, increased odds of behavioral, social, and emotional problems in children are associated with prenatal exposure to environmental stressors such as pollutants (Grandjean and Landrigan, 2014), maternal smoking or alcohol consumption (Polanska et al., 2015), gestational diabetes (Kong et al., 2018), maternal obesity (Sanchez et al., 2018), maternal immune activation (Gumusoglu and
Stevens, 2019), parental separation, low family income, and maternal psychological distress (D'Souza et al., 2018; Noonan et al., 2018; van der Waerden et al., 2017; van der Waerden et al., 2015). In contrast, having older siblings (de La Rochebrochard and Joshi, 2013) and being breastfed (Heikkila et al., 2011) appear to be associated with lower odds of behavioral problems later in life. Although the impact of preand post-natal environmental factors on neurodevelopment and behavior has been recognized for many years, the underlying mechanisms remain unknown. Yet, it is commonly accepted that early life adversity impacts either directly or indirectly the child's immune system and contributes altered cytokine production (O'Connor et al., 2019; Pedersen et al., 2018).

Cytokines are small signaling molecules which act by binding to their cognate receptors at the surface of target cells. While most

\footnotetext{
*Corresponding author at: Institut de Pharmacologie Moléculaire et Cellulaire, 660 Route des Lucioles, 06560 Valbonne, France.

E-mail address: davidovic@ipmc.cnrs.fr (L. Davidovic).

${ }^{1}$ Equal contribution
} 
cytokines are known for their role during immune responses, they also regulate many biological functions in the body. Both pre-clinical and clinical studies have pointed to a critical role of cytokines in neurodevelopment and brain function, both in physiological and pathological conditions (Morimoto and Nakajima, 2019). Indeed, many cell types in the brain including microglia, astrocytes and neurons express cytokine receptors and can therefore be regulated by cytokines (Morimoto and Nakajima, 2019). This is the case of microglia which are brain-resident macrophages that sense and respond rapidly to alterations in brain homeostasis and integrate brain response to threats (Frank et al., 2019). Microglia also shape neuronal circuits (Morimoto and Nakajima, 2019), regulate the size of the neural precursor cell pool (Cunningham et al., 2013), and promote synaptic pruning during neurodevelopment (Filiano et al., 2016). As microglia express several receptors including those of interleukin (IL)-1 $\beta$, IL-6, IL-10 and tumour necrosis factor (TNF)- $\alpha$, their functions are tightly regulated by these cytokines as demonstrated in rodent models of anxio-depression (Dantzer et al., 2008; Harden et al., 2006).

Cytokines may also act directly on neurons and neurotransmission (Morimoto and Nakajima, 2019). For example, TNF- $\alpha$ secreted by astrocytes controls neurotransmitter receptors trafficking at the synapse, thereby directly regulating neurotransmission in the hippocampus, cortex and striatum (Beattie et al., 2002; Lewitus et al., 2014; Santello et al., 2011; Stellwagen and Malenka, 2006). Tnf-deficient mice display elevated hippocampal neurogenesis (Iosif et al., 2006) and TNF- $\alpha$ modulates survival, proliferation, and neuronal differentiation of neural progenitors (Bernardino et al., 2008). The absence of TNF- $\alpha$ conditions reduced fear response in mice (Zupan et al., 2017), as well as enhanced spatial memory associated with increased hippocampal neurogenesis (Liu et al., 2014a). Also, IL-15 produced by astrocytes regulates neurogenesis (Gomez-Nicola et al., 2011) and facilitates $\gamma$-aminobutyric acid (GABA)-ergic neurotransmission in the hippocampus (He et al., 2010). Furthermore, interferon (IFN)- $\gamma$ promotes neuronal connectivity and influences social behavior (Filiano et al., 2016). Finally, IL-4 is essential for learning and memory processes, likely by inducing the production of brain derived neurotrophic factor (BDNF) (Derecki et al., 2010) Altogether, these studies suggested that proper levels of cytokines in the brain surroundings and in its parenchyma are required for the optimal establishment of brain circuitry and adapted behavioral responses (Filiano et al., 2015).

The blood levels of cytokines are often altered in neurodevelopmental and psychiatric disorders, supporting the notion that cytokines are involved in the etiopathology of these diseases (Dantzer, 2018; Mitchell and Goldstein, 2014). In young individuals presenting psychiatric symptoms and subjected to a task involving reward circuitry activation, the circulating levels of 41 cytokines associate with brain activation patterns (Bradley et al., 2019), suggesting that peripheral cytokines can regulate behavior. Although both preclinical and clinical studies suggested that IL-1 $\beta$, IL-4, IL-6, IL-15, IFN- $\gamma$ and TNF- $\alpha$, regulate neurodevelopment, behavior and brain function, whether any of these cytokines is associated with behavioral problems in children is unknown. Hence, there is a need for exploring possible associations between these specific cytokines and behavioral dimensions in children. The fact that most cytokines interact with and are regulated by other cytokines makes this issue more complex and requires a systematic approach. To identify possible associations between specific cytokines and behavioral dimensions in children, we have taken advantage of clinical data and serum samples collected from 5-year-old children enrolled in the French mother-child EDEN cohort (Heude et al., 2016). In this cross-sectional study, we have studied potential associations between 27 cytokines and five dimensions of a child's behavior: emotions, conduct, hyperactivity/inattention, peer relationships and social behavior.

\section{Methods and materials}

\subsection{Study design}

The EDEN (Etude sur les Déterminants pré- et postnataux du développement psychomoteur et de la santé de l'Enfant) mother-child cohort was set up to assess the influence of pre- and post-natal determinants on the child psychomotor development and health (Heude et al., 2016). Pregnant women were recruited before 24 weeks of gestation at the Obstetrics and Gynecology department of the University Hospitals of Nancy and Poitiers, France. Enrollment spanned over 27 months in each center. Exclusion criteria included multiple pregnancies, a known history of diabetes, the inability to speak and read French or plans to move out of the study region in the following 3 years. Among 3,758 eligible women, 2002 (53\%) were enrolled in the study. During pregnancy and after birth $(4,8,12,24$ months, 3,4 and 5 years), sociodemographic and biomedical data on the mother and child were gathered (i) from medical records, (ii) in face-to-face interviews with the mother, and (iii) by mother's self-completed questionnaires. Participants to the EDEN study were representative of national estimates with regards to average age, proportion of unmarried couples, parental socio-demographic characteristics, offspring birth weight and prematurity rate, except for higher maternal education level (Blondel et al., 2012; Heude et al., 2016). Over the follow-up period, attrition rates were higher in families in which the mother was young, had low educational level and low income, did not live with the child's father, presented higher levels of caffeine intake, smoked tobacco, had psychological difficulties in pregnancy and whose child did not have low birth weight.

\subsection{Study sample}

Among the 2002 pregnant women included in the EDEN study, 1907 were still followed-up at delivery. Mother-child pairs were excluded for the following reasons: miscarriage $(\mathrm{n}=11)$, in utero death $(n=7)$, abortion for medical reasons $(n=2)$, loss to follow-up $(n=14)$, moving away $(n=8)$, mother changing their mind $(n=51)$, and not meeting inclusion criteria $(n=2)$. Birth data were obtained from 1,899 mother-infant pairs. Among the 1907 children born in the cohort, 1255 children were still followed at 5 years. In the context of this specific study, our study sample consisted of 786 5-year-old children.

\subsection{Measurements of serum cytokine levels}

Venous blood was obtained from 5 to 6 (mean age 5.5)-year-old children and allowed to clot for $1 \mathrm{~h}$ at room temperature prior to centrifugation $(1500 \times \mathrm{g}, 10 \mathrm{~min})$. Serum samples were stored at $-80^{\circ} \mathrm{C}$. Serum concentrations of cytokines were determined for the 786 individuals of our study sample. Serum samples were thawed on ice only once, and assayed using kits and reagents from two batches. All assays were completed within a 4 week period by the same investigator, blind to the samples' class. All assays were performed according to the manufacturer's instructions. Concentrations of Chemokine (C-C motif) ligand (CCL) 2, CCL3, CCL4, CCL11, CCL13, CCL17, CCL26, C-X-C motif chemokine 10 (CXCL10), Granulocyte-Macrophage Colony-Stimulating Factor (GM-CSF), IFN- $\gamma$, IL-1 $\alpha$, IL-1 $\beta$, IL-2, IL-4, IL-5, IL-6, IL-7, IL-8, IL-10, IL-12p40, IL-12p70, IL-13, IL-15, IL-16, IL-17A, Tumor Necrosis Factor (TNF)- $\alpha$, and TNF- $\beta$ were measured using the following v-plex ${ }^{\circledR}$ multiplex immunoassays: Proinflammatory Panel 1, Cytokine Panel 1 and Chemokine Panel 1 (Meso Scale Diagnostics, Rockville, USA). On each of the 96-well plates, seven serial dilutions of standards and buffer 
only (in duplicates) were run together with 80 samples (run in singlicate) on the Sector Imager 2400 plate reader (Meso Scale Diagnostics, Rockville, USA). Concentrations of biomarkers in each sample were interpolated from standard curves generated with a five-parameter logistic regression equation in Discovery Workbench 3.0 software (Meso Scale Diagnostics, Rockville, USA). For cytokine levels below the lower limit of detection (LLOD), we imputed a value equal to half the LLOD value indicated by the manufacturer. Cytokines presenting concentrations below LLOD in more than $15 \%$ of the samples (i.e. CCL26, IL-1 $\alpha$, IL-1 $\beta$, IL-2, IL-12p70, IL-4, IL-5, IL-13, GM-CSF) were excluded from downstream analyses (Tab. S1). For the 18 remaining biomarkers, we assessed the quality of our measurements by retrospectively calculating intra-run and inter-runs coefficients of variations (CV), based on the concentrations obtained for each of the 7 serially diluted standards across the 11 plates used to analyze the 786 serum samples. The intraor inter-CVs were below $20 \%$ within the range of cytokines concentrations comprised between the $1 \%$ and $99 \%$ percentiles of our sample (Tab. S2). CVs below $20 \%$ comply with the US FDA recommendations regarding validation of ligand-binding assays (https:// www.fda.gov/regulatory-information/search-fda-guidance-documents/ bioanalytical-method-validation-guidance-industry).

\subsection{Assessment of the child's outcome at 5 years}

Child's behavioral outcome was assessed using the SDQ and was completed by the mother when the child was between 5 and 6 years of age (Goodman, 2001). The SDQ is a broadly used psychometric instrument (Cox et al. 1987; Goodman, 1997, 2001) and entails five scales measured by five items each: emotional symptoms (fears, worries, clingy, unhappy, somatic), conduct problems (lies, fights, tempers, steals, obedient), hyperactivity/inattention (distractible, persistent, restless, fidgety, reflective), peer relationship problems (good friend, popular, best with adults, solitary, bullied) and prosocial behavior (helps out, caring, considerate, kind to kids, shares). All items refer to the past 6 months or the current school year and are scored 0 (never), 1 (sometimes true), or 2 (certainly true). The SDQ items scored on the 3point scale can be combined into 4 difficulties subscales (emotional symptoms, conduct problems, hyperactivity/inattention, peer relationship problems) and one strength subscale (prosocial behavior). To stratify children at high-risk and low-risk for behavioral symptoms, we dichotomized the SDQ difficulties subscales and the prosocial subscale at the $85^{\text {th }}$ upper percentile and $15^{\text {th }}$ lower percentile respectively. Such a dichotomization was used in previous studies (Melchior et al., 2015; Philippat et al., 2017) and in studies using similar psychometric scales (de Winter et al., 2005; Huisman et al., 2008; Schneiders et al., 2003; Amone-P'Olak et al., 2009). Because SDQ scores are discrete, this led us to use cutoffs of $4,5,6,3$ and 6 for emotional symptoms, conduct problems, hyperactivity/inattention, peer relationship problems and prosocial behavior, respectively. Using these cutoffs, the high-risk class for these behavioral problems comprised $21.5 \%, 16.1 \%, 17.4 \%, 14.6 \%$ and $17.3 \%$ of the children respectively (Supplementary Fig. 1). In his seminal paper, Goodman recommended to use cutoffs of 4, 3, 6, 3 and 5 to stratify children in a "normal" and a "borderline-abnormal" class for emotional symptoms, conduct problems, hyperactivity/inattention, peer relationship problems and prosocial behavior, respectively. Therefore, we used the same cutoffs as those recommended by Goodman for emotional symptoms, hyperactivity/inattention and peer relationship problems. In contrast, the cutoffs of 5 and 6 that we used for conduct problems and prosocial behavior respectively were different than those recommended by Goodman. We made this decision because the cutoffs recommended by Goodman would have resulted in a high-risk class consisting of $43.9 \%$ and $7.39 \%$ of children respectively, i.e. much higher and much lower than the targeted 15th upper percentile.

\subsection{Covariates and confounding factors}

We selected maternal, perinatal, psychosocial and child's variables that could impact child development and/or serum cytokine levels (Fig. 1). Previous studies have identified psychosocial and clinical variables associated with altered odds of behavioral abnormalities in children (D'Souza et al., 2018; de La Rochebrochard and Joshi, 2013; Galera et al., 2015; Grandjean and Landrigan, 2014; Gumusoglu and Stevens, 2019; Heikkila et al., 2011 ; Kong et al., 2018; Noonan et al., 2018; Philippat et al., 2019; Philippat et al., 2017; Polanska et al., 2015; Sanchez et al., 2018; van der Waerden et al., 2017). Based on these studies, and considering that many of these variables can also influence cytokine production, we included several covariates. Maternal variables were: age at delivery (years), maternal pre-pregnancy body mass index (BMI in kg. $\mathrm{m}^{-2}$ ), gestational diabetes (yes/no), alcohol drinking during pregnancy (mean number of glasses/week), smoking throughout pregnancy (number of cigarettes/day), caffeine intake during pregnancy (mg caffeine/day) and maternal urinary /cervical/vaginal infection during pregnancy (yes/no). Perinatal variables were: breastfeeding (yes/no), gestational age (weeks of amenorrhea), delivery mode (vaginal, forceps/ventosa, C-section), birth weight (kg) and birth trimester. Psychosocial variables were: parental separation during pregnancy or after birth (biological father not living with the mother and child: yes/ no), maternal and paternal education duration (years), family income from pregnancy to age 5 (mean of the seven class numbers: $0,<800 €$ / month; 1, 801-1500€/month; 2, 1501-2300€/ month; 3, 2301-3000€/ month; 4, 3001-3800€/month; 5, 3801-4500€/month; 6, greater than $4500 € /$ month), financial difficulties from pregnancy to age 5 (yes/ no), number of older siblings and stimulations of the child at home (mean score of three subscales of the Home Observation for Measurement of the Environment inventory (Bradley and Caldwell, 1977) at 5 years: language stimulation, academic stimulation, variety of experimentation), and record of depression (yes/no) either during pregnancy or post-pregnancy. Symptoms of maternal depression were detected using the Center for Epidemiological Studies Depression questionnaire (CES-D (Radloff, 1977)) at 24-28 weeks of amenorrhea or with the Edinburgh Postnatal Depression Scale (EPDS (Cox et al., 1987)) at 4, 8, and 12 months post-partum. Child-related variables were: allergies (yes/no), BMI (kg.m ${ }^{-2}$ ) at age 5 and the sex (female/male). We also included the blood sampling time which could impact cytokine levels.

\subsection{Univariate statistics}

Comparison analyses of variables in the low- versus high-risk group based on each SDQ subscore were performed using the Wilcoxon-Mann \& Whitney $U$ test for numerical variables or with the Chi-square test for categorical variables, with Benjamini \& Hochberg's multiple testing correction (False Discovery Rate). Correlations between concentrations of cytokine pairs were performed using Spearman's $\rho$ correlation coefficient rank test with Benjamini \& Hochberg's multiple testing correction. Statistical significance was set at a corrected p-value of $<0.05$.

\subsection{Association studies}

An overview of the methodological workflow is presented in Supplementary Figure 2 and detailed hereafter:

\subsubsection{Multiple imputation (MI)}

Missing data in the original dataset were imputed using the Multivariate Imputation by Chained Equations (MICE) procedure in $\mathrm{R}$ (van Buuren and Groothuis-Oudshoorn, 2011). The outcome was used in the multiple imputation process, as it produces more precise estimates than standard multiple imputation. To minimize the bias introduced by a mis-specified model for imputing the missing outcomes, observations with imputed outcomes were excluded from subsequent 


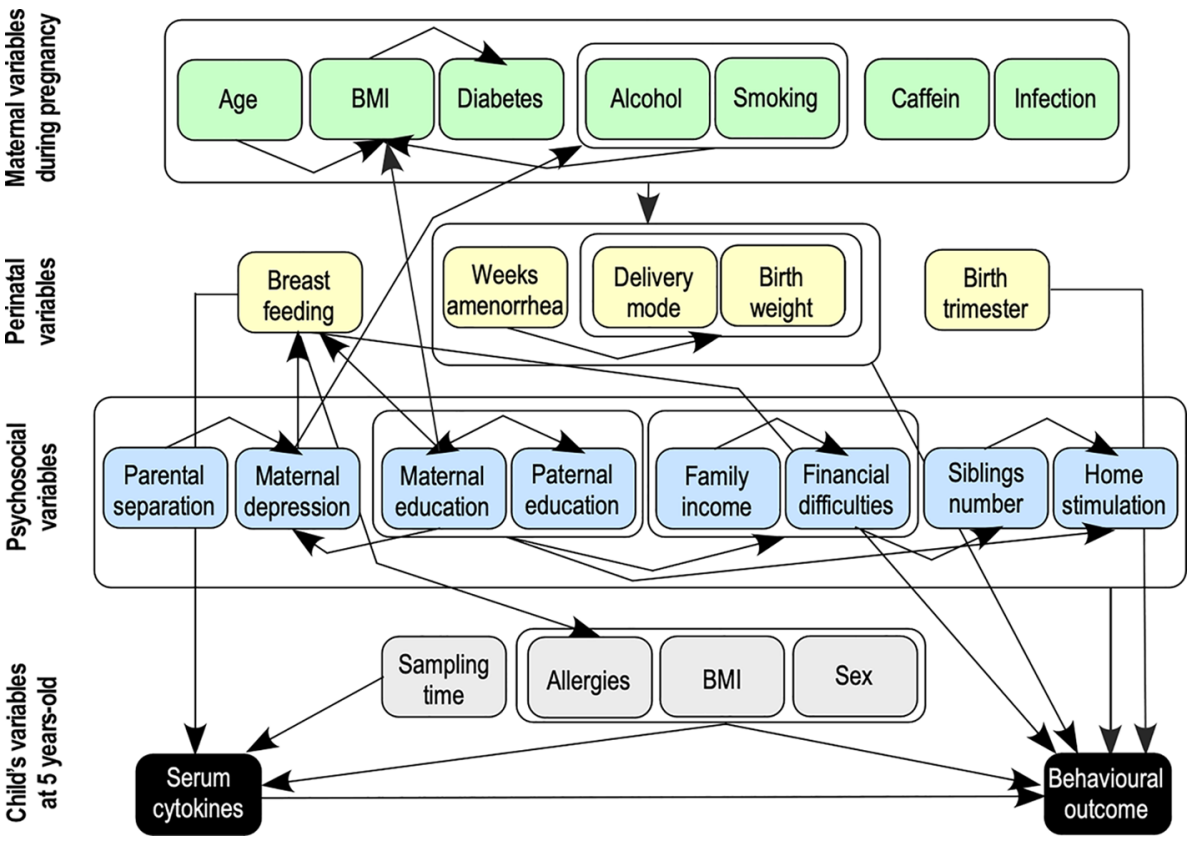

Fig. 1. Relationships between covariates, confounders, predictors and outcomes. Diagram showing possible inter-relations between selected maternal, perinatal, psychosocial and child's variables and serum cytokine levels (predictors) and/or child's behavioral outcome. Arrows depict documented or supposed influence between variables. BMI, body mass index. analyses (Kontopantelis et al., 2017). As per the recommended procedure (Graham et al., 2007) regarding power considerations, we generated 40 independent MI datasets.

\subsubsection{Resampling $(R)$}

Traditional methods do not provide valid confidence intervals or $\mathrm{p}$ values for testing the significance of penalized regression coefficients. As an alternative, the non-parametric bootstrap can be used for inference in applications of penalized regression (Abram et al., 2016). The bootstrap step involved 100 resamplings for each of the $40 \mathrm{MI}$ datasets (with replacement) to create 100 different samples of each MI dataset, with the full sample size. The regression model was subsequently fitted to each of the $40 \times 100$ samples of data.

\subsubsection{Variables selection using the Elastic Net}

The CARET (Kuhn, 2008) and GLMNET (Friedman et al., 2010) R packages were used to implement Elastic Net penalized (or regularized) logistic regression models with the aim of performing variable selection, leading to sparser final model, in agreement with previous recommendations (Pavlou et al., 2016). The Elastic Net framework uses linear models with penalties to avoid extreme parameters that may cause overfitting while simultaneously performing variable selection and addressing the issue of multi-multicollinearity (correlation). Optimal $\lambda$ and $\alpha$ hyperparameters for the elastic net algorithm were chosen via 10 -fold cross-validation, with the optimal tuning hyperparameters values chosen to maximize the Area Under the Receiving Operator Curve (AUROC). The Elastic Net is not a deterministic process since variables associated with the outcome may not be selected in every run. For this reason, the optimization steps were repeated. In the case of the complete cases (CC) dataset, to optimize the stability of results we repeated the 10 -fold cross-validation 1000 times with random dataset partitions. For MI resampling (MI-R) analyses, 40x100 models were implemented and the hyper parameters optimization step was repeated 3 times, leading to 12,000 models. For analysis of both CC and MI-R datasets, the Elastic Net was used to select a subset of variables by calculating the Variable Inclusion Probability (VIP), i.e. the percentage of times each variable was kept in the model (i.e. with an associated coefficient different from zero) out of the 1000 and 12,000 models, respectively. In the absence of asymptotically valid p-values which are (still) not available in high-dimensional regression, the VIP can be interpreted as the posterior probability of including a variable in the model and is used as a measure of the stability of the association (Bunea et al., 2011). After defining an appropriate threshold, the VIP is used to select predictors for follow-up analyses. Depending on the study, determining an appropriate threshold for the VIP can be challenging. In their landmark paper, Bunea et al. recommended a "conservative threshold of $50 \%$ " because their goal was "not to miss any possibly relevant predictors" (Bunea et al., 2011). However, this 50\% threshold increases the risk of false positives. In this study, we set a stringent VIP threshold at $90 \%$ to identify variables stably associated with behavioral dimensions (cf. 3.).

\subsubsection{Influential individuals and outliers}

We sought to estimate the influence of each individual on the different models by calculating the Cook's distance. For each SDQ outcome, we considered the subset of variables selected by the Elastic net using a VIP threshold of $90 \%$ on the $40 \mathrm{MI} \times 100$ bootstraps, and calculated the Cook's distance for each individual using logistic regression. As a result, we obtained for each individual the percentage of the runs in which it appeared as influential. Considering a conservative threshold of $50 \%$, the number of influential individuals in the emotion, conduct, hyperactivity, peer problem and prosocial dimensions were 24 (out of 786), 49 (out of 785), 34 (out of 786), 54 (out of 785) and 38 (out of 784) respectively. In each dimension, all influential individuals belonged to the high-risk class. There was very little overlap between dimensions, meaning that most individuals influential in one dimension were not influential in the others. The distributions of cytokine levels were similar between influential and non-influential individuals suggesting that none of the influential individuals was an outlier in terms of cytokine levels. Since we had no objective biological ground to exclude influential individuals from the study, we decided to retain all individuals in analyses.

\subsection{Ethics}

The EDEN cohort received approval from the Ethical Research Committee (CCPPRB) of Bicêtre Hospital and from the French National Data Protection Agency (CNIL). Informed written consent was obtained from parents at the time of enrollment and after delivery. 


\section{Results}

In this study, a penalized logistic regression method was used to identify cytokines whose blood levels were associated with increased or reduced risk of developing behavioral difficulties in 5-year-old children followed from birth. This population-based pediatric cohort consisted of 786 mother-child pairs from the French EDEN cohort in which mothers were enrolled at mid-pregnancy (Heude et al., 2016) and whose child's blood samples and SDQ psychometric scores were available at the age of 5 years. To identify children at high-risk of developing problems in each of the five SDQ behavioral dimensions, we dichotomized subscores at the 85th percentile for the 4 difficulties subscales of the SDQ and at the 15th lowest percentile for the prosocial strength subscore (Supplementary Fig. 1). The distribution of SDQ scores in each dimension was consistent with that of previous studies (Goodman, 1997, 2001; Melchior et al., 2015).

We assessed 786 serum samples for levels of 27 different cytokines, including several known to regulate brain function or development in animal studies and/or in humans. Nine cytokines (CCL26, GM-CSF, IL-1 $\alpha$, IL-1 $\beta$, IL-2, IL-4, IL-5, IL-12p70 and IL-13) had levels below LLOD in more than $15 \%$ of the samples (Table 1 ) and were therefore excluded from further analyses. For the 18 remaining cytokines, intra- and interassay CVs were below $20 \%$, compliant with US FDA recommendations for bioanalytical method validation regarding ligand-binding assays. We then investigated multicollinearity between these 18 cytokines using Spearman's correlation rank test with Benjamini-Hochberg's correction for multiple testing. All cytokines correlated with at least another one, and most correlated with several ones (Supplementary Table 2). For example, TNF- $\alpha$ correlated positively with CCL2, CCL3, CCL4, CCL11, CXCL10, IFN- $\gamma$, IL-6, IL-7, IL-10, IL-12p40, IL-15, IL-16 and IL-17A with correlation coefficients ranging from 0.1 to 0.5 .

Psychosocial characteristics of the study sample were comparable to previous national estimates with the exception of maternal education level which was higher (Blondel et al., 2012; Heude et al., 2016) (Table 2). For each behavioral dimension, univariate comparison analyses between low- and high-risk groups for the 42 variables (18 cytokines, 24 covariates) are shown in Supplementary Table 2. The two groups differed for a few variables: number of older siblings for emotional symptoms; financial difficulties, home stimulation and sex for conduct problems; paternal and maternal education, maternal age, smoking during pregnancy, family income, financial difficulties for hyperactivity; paternal education, family income and financial difficulties for peer problems.

While our study sample consisted of 786 mother-child pairs, the numbers of complete cases varied from 483 to 486 depending on the SDQ subscale (Supplementary Fig. 1). We applied the Elastic Net to the MI-R and CC datasets (Supplementary Fig. 1). As a measure of the stability of the association, we used the VIP which can be interpreted as the posterior probability of including a variable in the model (Bunea et al., 2011) (cf. 2.7.3, Supplementary Table 2). To define a threshold VIP for identifying cytokines associated with behavioral problems, we relied on the VIPs of psychosocial and clinical variables already known from previous studies to be associated with child's behavior: maternal depression, breastfeeding, gestational diabetes, and number of older siblings for emotional symptoms; maternal depression, financial difficulties, home stimulation, allergies and sex for conduct problems; paternal education, financial difficulties, number of older siblings and sex for hyperactivity/inattention; gestational age, birth weight, family income, financial difficulties, home stimulations for peer problems; and sex for prosocial behavior. Corresponding VIPs ranged from $91.3 \%$ to $100 \%$ and we therefore chose a threshold VIP of $90 \%$ for identifying cytokines associated with behavioral problems (Table 3). Accordingly, IL-7 was associated with higher odds of emotional symptoms, while IL8, IL-17A, and IL-10 were associated with lower odds (Table 3,

Table 1

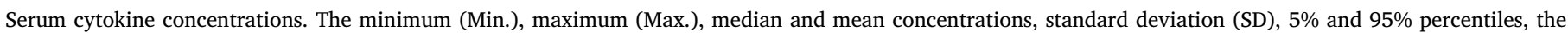

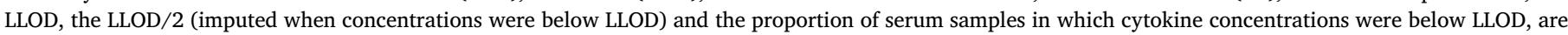
indicated for the 27 biomarkers assessed. Filled circles: variable included.

\begin{tabular}{|c|c|c|c|c|c|c|c|c|c|c|c|}
\hline Cytokines & $\begin{array}{l}\text { Min. (pg/ } \\
\text { mL) }\end{array}$ & Max. $(\mathrm{pg} / \mathrm{mL})$ & $\begin{array}{l}\text { Median } \\
(\mathrm{pg} / \mathrm{mL})\end{array}$ & $\begin{array}{l}\text { Mean (pg/ } \\
\mathrm{mL})\end{array}$ & $\begin{array}{l}\text { Standard } \\
\text { Deviation }\end{array}$ & $\begin{array}{l}5 \% \text { percentile } \\
(\mathrm{pg} / \mathrm{mL})\end{array}$ & $\begin{array}{l}95 \% \text { percentile } \\
(\mathrm{pg} / \mathrm{mL})\end{array}$ & $\begin{array}{l}\text { LLOD } \\
(\mathrm{pg} / \mathrm{mL})\end{array}$ & $\begin{array}{l}\mathrm{LLOD} / 2 \\
(\mathrm{pg} / \mathrm{mL})\end{array}$ & $\%<$ LLOD & $\begin{array}{l}\text { Included in } \\
\text { analysis }\end{array}$ \\
\hline CCL2 & 6.057 & 513.080 & 212.507 & 218.771 & 72.081 & 114.200 & 347.200 & 0.090 & 0.045 & 0 & • \\
\hline CCL3 & 3.044 & 281.272 & 13.414 & 16.173 & 18.309 & 7.058 & 28.960 & 3.020 & 1.510 & 2.41 & - \\
\hline CCL4 & 11.892 & 348.647 & 95.392 & 103.228 & 45.050 & 45.370 & 186.500 & 0.370 & 0.185 & 0 & 0 \\
\hline CCL11 & 14.728 & 799.430 & 129.983 & 139.775 & 66.368 & 60.600 & 248.800 & 3.260 & 1.630 & 0 & 0 \\
\hline CCL13 & 9.311 & 251.789 & 75.236 & 79.906 & 41.050 & 25.720 & 160.700 & 1.690 & 0.845 & 0.96 & 0 \\
\hline CCL17 & 17.247 & 27741.205 & 291.997 & 414.253 & 1095.564 & 76.650 & 928.500 & 0.220 & 0.110 & 0 & 0 \\
\hline CCL26 & 1.809 & 649.825 & 4.953 & 10.347 & 39.870 & 0.885 & 16.240 & 1.770 & 0.885 & 16.99 & \\
\hline CXCL10 & 15.247 & 2317.137 & 143.598 & 199.533 & 192.408 & 69.780 & 500.800 & 0.370 & 0.185 & 0 & $\bullet$ \\
\hline GM-CSF & 0.140 & 5.894 & 0.169 & 0.235 & 0.394 & 0.070 & 0.577 & 0.140 & 0.070 & 37.13 & \\
\hline IFN- $\gamma$ & 0.301 & 671.608 & 6.817 & 16.866 & 43.049 & 3.093 & 57.200 & 0.200 & 0.100 & 0.12 & - \\
\hline IL-1 $\alpha$ & 0.091 & 11.450 & 0.045 & 0.214 & 0.686 & 0.045 & 0.815 & 0.090 & 0.045 & 69.10 & \\
\hline IL-1 $\beta$ & 0.040 & 9.624 & 0.020 & 0.141 & 0.553 & 0.020 & 0.568 & 0.040 & 0.020 & 54.92 & \\
\hline IL-2 & 0.090 & 11.669 & 0.045 & 0.198 & 0.716 & 0.045 & 0.490 & 0.090 & 0.045 & 53.84 & \\
\hline IL-4 & 0.020 & 1.784 & 0.010 & 0.029 & 0.099 & 0.010 & 0.070 & 0.020 & 0.010 & 70.26 & \\
\hline IL-5 & 0.221 & 26.182 & 0.332 & 0.794 & 1.722 & 0.110 & 2.766 & 0.220 & 0.110 & 39.88 & \\
\hline IL-6 & 0.061 & 16.787 & 0.422 & 0.704 & 1.098 & 0.132 & 2.340 & 0.060 & 0.030 & 2.64 & 0 \\
\hline IL-7 & 2.236 & 87.172 & 21.950 & 22.920 & 9.592 & 8.838 & 39.180 & 0.160 & 0.080 & 0 & 0 \\
\hline IL-8 & 1.778 & 834.001 & 8.759 & 16.337 & 53.524 & 3.685 & 21.970 & 0.040 & 0.020 & 0 & 0 \\
\hline IL-10 & 0.031 & 50.849 & 0.434 & 0.741 & 1.935 & 0.186 & 2.082 & 0.030 & 0.015 & 0.36 & 0 \\
\hline IL-12p40 & 9.297 & 690.816 & 227.226 & 241.363 & 91.149 & 121.400 & 415.800 & 0.390 & 0.195 & 0 & 0 \\
\hline IL-12p70 & 0.112 & 15.924 & 0.055 & 0.226 & 0.707 & 0.055 & 0.693 & 0.110 & 0.055 & 51.68 & \\
\hline IL-13 & 0.250 & 57.815 & 0.120 & 0.640 & 2.634 & 0.120 & 2.089 & 0.240 & 0.120 & 66.67 & \\
\hline IL-15 & 0.208 & 5.444 & 1.881 & 1.939 & 0.487 & 1.299 & 2.790 & 0.170 & 0.085 & 0 & • \\
\hline IL-16 & 13.363 & 1462.262 & 177.650 & 193.762 & 89.143 & 103.200 & 321.600 & 2.830 & 1.415 & 0.12 & 0 \\
\hline IL-17 A & 0.767 & 52.420 & 3.174 & 3.804 & 3.213 & 1.344 & 7.769 & 0.740 & 0.370 & 0.24 & 0 \\
\hline TNF- $\alpha$ & 0.342 & 17.026 & 2.956 & 3.121 & 1.179 & 1.980 & 4.796 & 0.040 & 0.020 & 0 & - \\
\hline TNF- $\beta$ & 0.248 & 8.717 & 0.461 & 0.557 & 0.539 & 0.200 & 1.153 & 0.050 & 0.025 & 1.56 & 0 \\
\hline
\end{tabular}


Table 2

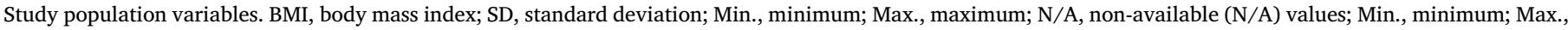
maximum.

\begin{tabular}{|c|c|c|c|c|c|}
\hline & & $N=786$ & $\%$ & Mean (SD) & N/A (\%) \\
\hline \multirow[t]{7}{*}{ Maternal variables } & Age at delivery (years) & & & $30.1(4.8)$ & 0 \\
\hline & Pre-pregnancy BMI $\left(\mathrm{kg} \cdot \mathrm{m}^{-2}\right)$ & & & $23.6(4.6)$ & 2.2 \\
\hline & Gestational diabetes & & 6.62 & & 0.1 \\
\hline & Alcohol drinking during pregnancy (mean glasses/week) & & $4.96^{1}$ & $0.6(1.5)$ & 0.4 \\
\hline & Smoking during pregnancy (cigarettes/day) & & $21.88^{2}$ & $1.1(2.8)$ & 3.1 \\
\hline & Caffeine consumption during pregnancy (mg/day) & & $91.47^{3}$ & $90.6(107.5)$ & 1.5 \\
\hline & Urinary/Cervical/Vaginal infection during pregnancy & & $74.94^{4}$ & & 0.3 \\
\hline \multirow[t]{10}{*}{ Perinatal variables } & Breastfeeding & & 68.45 & & 0 \\
\hline & Gestational age (weeks of amenorrhea) & & & $39.3(1.7)$ & 0 \\
\hline & Delivery mode & Vaginal & 76.08 & & 0.1 \\
\hline & & Forceps/Ventosa & 10.69 & & \\
\hline & & C-section & 13.10 & & \\
\hline & Birth weight (kg) & & & $3.3(0.5)$ & 0 \\
\hline & Birth trimester & $1^{\text {st }}($ Jan.-March $)$ & 23.79 & & 0 \\
\hline & & $2^{\text {nd }}$ (April-June) & 24.81 & & \\
\hline & & $3^{\text {rd }}$ (July-Sept.) & 26.59 & & \\
\hline & & $4^{\text {th }}$ (Oct.-Dec.) & 24.81 & & \\
\hline Psychosocial variables & Parental separation & & 10.18 & & 0.6 \\
\hline \multirow[t]{13}{*}{ (Pregnancy-Age 5) } & Maternal depression & & $38.17^{5}$ & & 7 \\
\hline & Maternal education (years) & & & $13.8(2.6)$ & 0.4 \\
\hline & Paternal education (years) & & & $13.1(2.6)$ & 7.5 \\
\hline & Family income & $<800 €$ & 1.40 & & 7.5 \\
\hline & & $801-1500 €$ & 7.12 & & \\
\hline & & $1501-2300 €$ & 18.58 & & \\
\hline & & $2301-3000 €$ & 24.55 & & \\
\hline & & $3001-3800 €$ & 22.77 & & \\
\hline & & $3801-4500 €$ & 12.85 & & \\
\hline & & $>4500 €$ & 11.20 & & \\
\hline & Family financial difficulties & & $34.61^{6}$ & & 15.3 \\
\hline & Number of older siblings & & & $0.9(1)$ & 10.9 \\
\hline & Home stimulations & & & $17.4(2.2)$ & 3.9 \\
\hline \multirow[t]{5}{*}{ Child's variables at 5-year-old } & Blood sampling time & & & Min.: 08:15 a.m. & \\
\hline & & & & $\begin{array}{l}\text { Mode: 09:00 p.m. } \\
\text { Max.:16:00 p.m. }\end{array}$ & 0.9 \\
\hline & Allergies & & 26.59 & & 3.6 \\
\hline & $\mathrm{BMI}\left(\mathrm{kg} \cdot \mathrm{m}^{-2}\right)$ & & & $15.4(1.3)$ & 0.1 \\
\hline & Sex & Female & 44.02 & & 0 \\
\hline
\end{tabular}

Footnotes: ${ }^{1} \%$ of women consuming at least 3 glasses of alcohol/week during pregnancy; ${ }^{2} \%$ of women smoking during pregnancy; ${ }^{3} \%$ of women consuming caffeine during pregnancy; ${ }^{4} \%$ of women declaring at least one infection during pregnancy; ${ }^{5} \%$ of women having experienced at least one depressive episode; ${ }^{6} \%$ of families having experienced financial difficulties at least once.

Supplementary Table 3). TNF- $\alpha$ was associated with lower odds of conduct problems, while CCL2 was associated with lower odds of hyperactivity/inattention. IL-15 was associated with higher odds of peer problems, while CXCL10 was associated with lower odds. IL- 6 was associated with increased odds of abnormal prosocial behavior, while CCL3 and IL-16 were associated with lower odds. Setting up an even more stringent threshold VIP (95\%), five out of these 11 cytokines remained associated (positively or negatively) with the outcome: IL-7, IL8, IL-10, TNF- $\alpha$ and CXCL10. Of note, several variables associated with altered odds of behavioral problems in the MI-R datasets were also identified when applying the Elastic Net regression model to the CC datasets (Supplementary Table 4). Thus, breastfeeding, maternal depression and number of older siblings were associated with emotional symptoms. This was also the case for maternal depression, financial difficulties, allergies, sex and TNF- $\alpha$ for conduct problems.

\section{Discussion}

To our knowledge, this cross-sectional study is the first to document associations between serum levels of individual cytokines and behavioral dimensions in 5-year-old children assessed by the SDQ. The SDQ is one the most common behavioral screening tool in children between 3 and 16 years of age (Stone et al., 2010). It has been used in large scale population-based birth cohorts such as the Copenhagen Child Cohort (CCC2000) (Niclasen et al., 2013) and the Danish National Birth Cohort (DNBC) (Elberling et al., 2010). This validated instrument allowed a large-scale study of possible associations between cytokines and behavioral outcome in young children. Because high scores in each of the SDQ subscale predict a high probability to enter a DSM IV diagnosis class later in life (Croft et al., 2015; Goodman, 2001; Russell et al., 2013; Russell et al., 2014), our results could be compared to those of studies exploring the role of cytokines in neurodevelopmental disorders. According to previous studies using other psychometric scales, scores over the 85th percentile also determine a class at high risk for clinical mental health disorders (de Winter et al., 2005; Huisman et al., 2008; Schneiders et al., 2003; Amone-P'Olak et al., 2009), thus making the possible clinical implication of our cross-sectional study more relevant from a public-health perspective.

\subsection{Cytokines, behavior and neurodevelopmental disorders}

High SDQ subscores for emotional symptoms are associated with DSM IV diagnoses of anxiety and depression (Goodman, 2001). In our study sample, IL-7 was associated with increased odds of emotional symptoms, while IL-8, IL-10 and IL-17A were associated with decreased odds. IL-7 is mainly known for its role in B and $\mathrm{T}$ lymphocyte 
Table 3

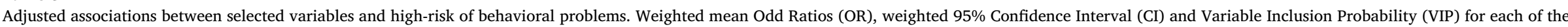

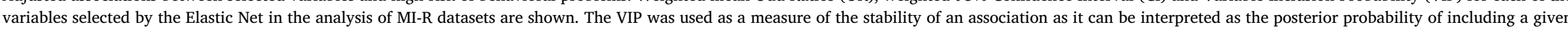

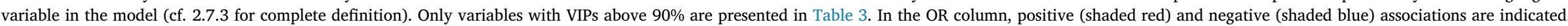
Supplementary Table 3 details the results for all 42 variables included.

\begin{tabular}{|c|c|c|c|c|c|c|c|c|c|c|c|c|c|c|c|c|}
\hline \multirow[b]{2}{*}{ Type } & \multirow[b]{2}{*}{ Variable ID } & \multicolumn{3}{|c|}{ Emotional symptoms } & \multicolumn{3}{|c|}{ Conduct problems } & \multicolumn{3}{|c|}{ Hyperactivity/Inattention } & \multicolumn{3}{|c|}{ Peer relationship problems } & \multicolumn{3}{|c|}{ Prosocial behavior problems } \\
\hline & & OR & $95 \%$ CI & VIP & OR & $95 \% \mathrm{CI}$ & VIP & OR & $95 \% \mathrm{CI}$ & VIP & OR & $95 \% \mathrm{CI}$ & VIP & OR & $95 \% \mathrm{CI}$ & VIP \\
\hline \multirow{3}{*}{$\begin{array}{l}\text { Maternal } \\
\text { variables }\end{array}$} & Age at delivery (years) & & & & & & & 0.854 & {$[0.701,0.993]$} & $91.6 \%$ & & & & & & \\
\hline & Gestational Diabetes & 1.34 & {$[1.012,1.853]$} & $94.1 \%$ & & & & & & & & & & & & \\
\hline & Caffeine consumption during pregnancy (mg/day) & 1.193 & {$[1.015,1.448]$} & $92.4 \%$ & & & & & & & & & & & & \\
\hline \multirow{5}{*}{$\begin{array}{l}\text { Perinatal } \\
\text { variables }\end{array}$} & Breastfeeding & 0.853 & {$[0.709,0.991]$} & $95.0 \%$ & & & & & & & & & & & & \\
\hline & Gestational age (weeks of amenorrhea) & & & & & & & & & & 0.801 & {$[0.646,0.97]$} & $94.4 \%$ & & & \\
\hline & Birth weight (kg) & & & & & & & & & & 1.226 & {$[1.015,1.558]$} & $90.2 \%$ & & & \\
\hline & Birth trimester: $1^{\text {st }}$ & & & & & & & & & & & & & 0.656 & {$[0.379,0.935]$} & $95.6 \%$ \\
\hline & Birth trimester: $2^{\text {nd }}$ & & & & & & & & & & 0.712 & {$[0.453,0.977]$} & $91.0 \%$ & & & \\
\hline \multirow{6}{*}{$\begin{array}{l}\text { Psychosocial } \\
\text { variables }\end{array}$} & Maternal depression (Pregnancy-Age 5) & 1.171 & {$[1.009,1.399]$} & $94.0 \%$ & 1.257 & {$[1.051,1.535]$} & $99.2 \%$ & & & & & & & & & \\
\hline & Paternal education (years) & & & & & & & 0.732 & {$[0.595,0.906]$} & $99.7 \%$ & & & & & & \\
\hline & Family income (Age 5) & & & & & & & & & & 0.802 & {$[0.632,0.985]$} & $93.8 \%$ & & & \\
\hline & Family financial difficulties (Pregnancy - Age 5) & & & & 1.246 & {$[1.026,1.561]$} & $97.1 \%$ & 1.231 & {$[1.025,1.519]$} & $94.8 \%$ & 1.355 & {$[1.059,1.749]$} & $98.6 \%$ & & & \\
\hline & Number of older siblings & 0.69 & {$[0.557,0.883]$} & $99.7 \%$ & & & & 0.828 & {$[0.671,0.977]$} & $94.9 \%$ & & & & & & \\
\hline & Home stimulations & & & & 0.822 & {$[0.681,0.978]$} & $98.5 \%$ & & & & 0.853 & {$[0.711,0.992]$} & $91.3 \%$ & & & \\
\hline \multirow{3}{*}{$\begin{array}{l}\text { Child's } \\
\text { variables } \\
\text { at } 5 \text { years }\end{array}$} & Blood sampling time & & & & 0.858 & {$[0.714,0.984]$} & $91.8 \%$ & & & & 0.822 & {$[0.655,0.972]$} & $96.5 \%$ & & & \\
\hline & Allergies & & & & 1.184 & {$[1.008,1.451]$} & $91.1 \%$ & & & & & & & & & \\
\hline & Sex:Male & & & & 1.538 & {$[1.238,1.894]$} & $100.0 \%$ & 1.349 & {$[1.112,1.663]$} & $99.8 \%$ & & & & 1.296 & {$[1.067,1.568]$} & $99.1 \%$ \\
\hline \multirow[t]{11}{*}{ Cytokines } & CCL2 & & & & & & & 0.825 & {$[0.667,0.981]$} & $93.3 \%$ & & & & & & \\
\hline & CCL3 & & & & & & & & & & & & & 0.839 & {$[0.65,0.987]$} & $90.7 \%$ \\
\hline & CXCL10 & & & & & & & & & & 0.788 & {$[0.604,0.962]$} & $96.6 \%$ & & & \\
\hline & IL-6 & & & & & & & & & & & & & 1.201 & {$[1.004,1.452]$} & $90.1 \%$ \\
\hline & IL-7 & 1.239 & {$[1.052,1.477]$} & $98.7 \%$ & & & & & & & & & & & & \\
\hline & IL-8 & \begin{tabular}{|l|}
0.84 \\
\end{tabular} & {$[0.69,0.974]$} & $97.0 \%$ & & & & & & & & & & & & \\
\hline & IL-10 & 0.751 & {$[0.537,0.962]$} & $98.4 \%$ & & & & & & & & & & & & \\
\hline & IL-15 & & & & & & & & & & 1.2 & {$[1.014,1.488]$} & $91.9 \%$ & & & \\
\hline & IL-16 & & & & & & & & & & & & & 0.853 & {$[0.688,0.995]$} & $90.6 \%$ \\
\hline & IL-17A & 0.886 & {$[0.742,0.992]$} & $91.0 \%$ & & & & & & & & & & & & \\
\hline & TNF- $\alpha$ & & & & 0.756 & {$[0.569,0.96]$} & $98.0 \%$ & & & & & & & & & \\
\hline
\end{tabular}


development (Dahl et al., 2014), and IL-8 is a chemotactic factor for neutrophils, basophils, and T lymphocytes (Baggiolini and Clark-Lewis, 1992). Noteworthy, increased serum levels of IL-7 have been reported in patients with Major Depressive Disorder (Dahl et al., 2014), and plasma levels of IL-8 correlated negatively with symptoms of anxiety (Janelidze et al., 2015). IL-10 is known for its ability to inhibit the secretion of pro-inflammatory cytokines (Saraiva et al., 2019). Il10deficient mice exhibit depressive-like symptoms and IL-10 treatment mitigates IL-1 $\beta$-induced anxiety and sickness behavior in adult male rats (Mesquita et al., 2008; Munshi et al., 2019). Our data are therefore in keeping with earlier reports suggesting a detrimental role for IL-7 and a beneficial role for IL-8 and IL-10 in mood disorders. The situation for IL-17A is less clear. IL-17A is involved in the clearance of extracellular bacteria, the maintenance of mucosal homeostasis and the control of autoimmunity (McGeachy et al., 2019). Th17 cells, the principal immune cell types that produce IL-17A, are more abundant in the blood of depressive patients compared to healthy controls (Beurel and Lowell, 2018). In mice, IL-17A and Th17 cells promote depressivelike behaviors (Beurel et al., 2018; Nadeem et al., 2017). In contrast, mice deficient in IL-17 exhibit increased hippocampal neurogenesis, excitatory synaptic transmission and intrinsic neuronal excitability (Liu et al., 2014b). Therefore, whether and how IL-17A regulates neurodevelopment and brain function remain to be further investigated.

Conduct problems in early childhood are associated with an increased risk of conduct disorder, oppositional defiant disorder or other disruptive behavioral disorders (Goodman, 2001). We show that TNF- $\alpha$ is associated with lower odds of conduct problems in 5-year-old children. TNF- $\alpha$ is mainly known as a pro-inflammatory cytokine that plays a critical role in the early steps of immune responses directed to bacteria (Holbrook et al., 2019). In the brain, TNF- $\alpha$ also appears to have non-immune roles. Indeed, glial TNF- $\alpha$ has been identified as a modulator of synaptic strength (Beattie et al., 2002; Lewitus et al., 2014; Stellwagen and Malenka, 2006) and TNF- $\alpha$ modulates the survival, proliferation, and neuronal differentiation of neural progenitors (Bernardino et al., 2008). These data, together with ours, suggest that TNF- $\alpha$ is required for optimal brain functioning.

The hyperactivity/inattention SDQ subscore captures key symptom domains for a DSM IV diagnosis of ADHD (Goodman, 2001). In our study, CCL2 was associated with increased odds of hyperactivity/inattention in children aged 5. CCL2 is a chemokine mainly known for this ability to recruits inflammatory monocytes to inflamed tissues (Deshmane et al., 2009). To our knowledge, CCL2 has not been associated with ADHD before. However, given the critical role of CCL2 in the proinflammatory process and its reported association with ASD (Han et al., 2017), our results may suggest a link between inflammation and hyperactivity/inattention.

Peer problems are observed in ASD patients (Goodman, 2001). In our study, serum CXCL10 in 5-year-old children was associated with lower odds of peer problems. CXCL10 is a chemoattractant for monocytes and T cells (Karin and Razon, 2018), but it also mediates sickness behavior and cognitive dysfunctions after viral infection in mice (Blank et al., 2016). Our results are in keeping with an earlier report showing lower serum levels of CXCL10 in ASD patients compared to neurotypical controls, and a positive association of CXCL10 with social behaviors (Shen et al., 2016). In contrast, serum IL-15 was associated with higher odds of peer problems. IL-15 is a member of the IL-2 family of cytokines whose signaling pathways are at the crossroads between innate and adaptive immunity, it is also produced by astrocytes and neural progenitors, regulates neurogenesis and has anti-depressive effects in mice (Pan et al., 2013). More studies are required to investigate the role of IL-15 in social behavior.

A low SDQ prosocial subscore is a good predictor of ASD diagnosis in children (Russell et al., 2013; Russell et al., 2014). Here we show that the pro-inflammatory cytokine IL- 6 is associated with increased odds of abnormal prosocial behavior in 5-year-old children. Several studies have pointed out a crucial role for IL- 6 in the development of autistic- like behaviors in mice, and notably deficits in social interaction (Smith et al., 2007; Wu et al., 2017). Increased IL-6 levels have been observed in children with ASD, as compared to neurotypical controls (Saghazadeh et al., 2019), further supporting a role for IL-6 in the modulation of social behavior. In contrast, we show that CCL3, a potent pyrogenic chemoattractant for macrophages, monocytes and neutrophils (Maurer and von Stebut, 2004) is associated with decreased odds of abnormal prosocial behavior in our study. ASD patients exhibited lower levels of CCL3, which was positively associated with social behaviors (Shen et al., 2016). Our results thus support a relationship between CCL3 and social behavior. In our study, IL-16, a cytokine shown to recruit and activate CD4-expressing cells, including subpopulations of $\mathrm{T}$ cells, monocytes, eosinophils, and dendritic cells (Glass et al., 2006), was associated with decreased odds of abnormal prosocial behavior in 5-year-old children. Treatment of murine neuronal cultures with IL-16 modulates neuronal excitability and synaptic activity, suggesting that IL-16 is involved in neurotransmission control (Hridi et al., 2019). It is difficult to reconcile the previous findings with those of a recent study showing that ASD patients have higher frequencies of IL16 expressing blood mononuclear cells compared to neurotypical controls (Ahmad et al., 2019). Further studies are warranted to decipher the possible links between IL-16 and social behavior.

\subsection{Possible mechanisms}

Since association does not imply causation, it remains to be demonstrated whether peripheral cytokines directly contribute to modulate brain functions and behavior. Although evidence for a causal relationship is lacking in humans, animal studies have pointed to several pathways by which peripheral cytokines could impact brain functions. First, peripheral cytokines could impact brain function indirectly either by activating peripheral afferent neural fibers (Zanos et al., 2018) or by binding to their cognate receptors on meningeal and lymphatic epithelial cells, eventually inducing the production of cytokines or other immune mediators such as prostaglandins and nitric oxide that will diffuse or be transported to the brain parenchyma (Dantzer, 2018; Pollmacher et al., 2002). Alternatively, cytokines can be transported from the periphery to the brain via the circumventricular organs, the brain-blood-barrier or the CNS lymphatic system, as demonstrated for TNF- $\alpha$, IL-1- $\beta$ and CCL2 (Banks, 2015; Norris and Kipnis, 2019). In the brain parenchyma, these cytokines could directly regulate both neurodevelopment and neurotransmission. For example, TNF- $\alpha$ promotes neurogenesis (Bernardino et al., 2008; Golan et al., 2004) and synaptic scaling (Beattie et al., 2002; Lewitus et al., 2014; Santello et al., 2011; Stellwagen and Malenka, 2006). Also, astrocytic IL-15 controls neurogenesis (Gomez-Nicola et al., 2011) and modulates GABAergic neurotransmission (He et al., 2010).

Pro-inflammatory cytokines such as TNF- $\alpha$ or IL- 6 can have a deleterious effect on brain functions and behavior when their level is increased by several folds as the result of severe brain injury or infection (Pollmacher et al., 2002; Quan, 2014). However, this study as well as others using cytokine-deficient mice suggest that a negative deviation from baseline concentration could also be detrimental to brain functions and behavior. The impact of cytokines on brain functions appears complex and intertwined, its negative or positive valence depending on both their nature and their relative abundance towards other cytokines (Becher et al., 2017). In this context, it is tantalizing to speculate that baseline levels of specific cytokines are required for optimal brain functions and that deviating from these levels either in one direction of the other is detrimental.

\subsection{Penalized regression for datasets with high-dimensionality}

One originality of this study is the use of the Elastic Net penalized regression framework, a robust methodology adapted to datasets with high-dimensionality of data, which has good performance when the 
number of events per variable (EPV) is low, performs variable selection and computes estimates, while addressing the issue of multicollinearity among variables (Bunea et al., 2011; Pavlou et al., 2016). While Elastic Net was first used to analyze omics data in genetic studies (Waldmann et al., 2013), it has been recently applied to neuroimaging (Abram et al., 2016; Bunea et al., 2011) and epidemiological data (Lu and Petkova, 2014; Philippat et al., 2019; Vasquez et al., 2016; Walter and Tiemeier, 2009). Following variable selection, it is a common practice to apply classical statistical inference, e.g. computing coefficients estimates, confidence intervals and p-values, on the same datasets. This may result in misleading conclusions because the statistical inference theory assumes data to be generated from a known model, and not that the model is selected based on the data used for inference (Leeb and Potscher, 2006). For this reason, we chose to readily interpret the Elastic Net penalized odd-ratios, keeping in mind that we could underestimate the size of the variable effect on the outcome. Consequently, we did not compute confidence intervals and p-values but rather used the weighted mean and weighted $95 \% \mathrm{CI}$ of the odd-ratios and used the VIP as an estimate of the stability of the reported associations. As the size of epidemiological datasets tends to increase, we believe that the Elastic Net should be used more often for both variable selection and coefficients estimation, especially when there is no $a$ priori or compelling evidence for selecting a small set of these variables. In previous studies, maternal depression and emotional distress appeared to be risk factors for emotional problems (D'Souza et al., 2018), while having older siblings could be protective (de La Rochebrochard and Joshi, 2013). Also, being a male is a risk factor for neurodevelopmental disorders (Davis and Pfaff, 2014) and low family income/financial difficulties are risk factors for abnormal socioemotional development of the child (Noonan et al., 2018). We consistently found these covariates to be associated with difficulties in at least one dimensions of behavior. The later observations lend support to the pertinence of our variable selection process.

\subsection{Limitations}

Our study has several limitations. First, and although we have adjusted for many covariates known or suspected to impact cytokine levels or behavioral outcome, we did not include other potential confounders which were not collected during the course of the EDEN study. This is for example the case for medications, infections and intestinal microbiota composition at the time of blood sampling. Second, the association coefficients and odds ratios that we computed using the Elastic Net method may underestimate the effect size of the variables on the behavioral outcomes because these are shrunken by the method. Therefore, these coefficients must be interpreted with caution. Third, the current study relies on serum samples collected at the age of 5 and is therefore based on cytokines measured at a single time point and in a sole biological matrix, serum. Therefore, we could not investigate the stability of our results overtime and over other biological matrices derived from peripheral blood, such as plasma. Fourth, despite our study sample being within the national estimates for most socioeconomic factors (Blondel et al., 2012; Heude et al., 2016), maternal level of education in the EDEN cohort was higher and may limit the generalization of our findings. Lastly, our results have not yet been replicated in an independent mother-child cohort, which would be warranted to validate our findings.

\section{Conclusions and prospects}

This study is the first to identify blood cytokines associated with specific behavioral problems in children. Serum levels of cytokines suspected or known to play a role in neurodevelopment and brain functions, such as IL-6, IL-10, IL-15, IL-17A, and TNF- $\alpha$, were indeed associated with behavioral outcome in children. Furthermore, blood levels of cytokines poorly studied in this context - including IL-7, IL-8,
IL-16 and the chemokines CCL2, CCL3 and CXCL10 - were associated with behavioral outcome in children. Further validation of the associations between cytokine levels and behavior is necessary, including analysis of other features, such as childhood infections and use of steroids. On another topic, several psychosocial variables previously associated with behavioral outcome in children were confirmed in our study sample. It would be interesting to investigate the association between these variables, and more specifically maternal depression, parental separation and poor socioeconomic status, with cytokine levels. Such a study may help unravel the mechanisms whereby early life adversity contributes altered cytokine production and lifelong psychiatric disorders (O'Connor et al., 2019; Pedersen et al., 2018). Whether the associations disclosed by this study reflect causal relationships, have prognostic value, or are merely phenomenological, would require longitudinal studies initiated prior to diagnosis of neurodevelopmental disorders and ideally pursued several years after clinical disease onset.

\section{Acknowledgements}

We thank the families who participated to this study. We thank the midwife research assistants for data collection, the psychologists and the data entry operators. We thank the EDEN Mother-Child Cohort Study Group which includes the following members: I. Annesi-Maesano, J.Y. Bernard, J. Botton, M.A. Charles, P. Dargent-Molina, B. de LauzonGuillain, P. Ducimetière, M. de Agostini, B. Foliguet, X. Fritel, A. Germa, V. Goua, R. Hankard, M. Kaminski, B. Larroque, N. Lelong, J. Lepeule, G. Magnin, L. Marchand, C. Nabet, F. Pierre, R. Slama, M.J. Saurel-Cubizolles, M. Schweitzer, and O. Thiebaugeorges. We thank the members of the Centre de Calculs Interactifs de l'Université de Nice Sophia-Antipolis for access to their computing facility. We thank Cecil Czerkinsky for critical reading and editing of the manuscript. LD, CD and $\mathrm{BH}$ acknowledge the generous support of the Fondation de France AAP Autisme et neurodéveloppement (France).

\section{Appendix A. Supplementary data}

Supplementary data to this article can be found online at https:// doi.org/10.1016/j.bbi.2020.01.005.

\section{References}

Abbott, P.W., Gumusoglu, S.B., Bittle, J., Beversdorf, D.Q., Stevens, H.E., 2018. Prenatal stress and genetic risk: How prenatal stress interacts with genetics to alter risk for psychiatric illness. Psychoneuroendocrinology 90, 9-21.

Abram, S.V., Helwig, N.E., Moodie, C.A., DeYoung, C.G., MacDonald 3rd, A.W., Waller, N.G., 2016. Bootstrap enhanced penalized regression for variable selection with neuroimaging data. Front Neurosci 10, 344.

Ahmad, S.F., Ansari, M.A., Nadeem, A., Bakheet, S.A., Al-Ayadhi, L.Y., Attia, S.M., 2019. Elevated IL-16 expression is associated with development of immune dysfunction in children with autism. Psychopharmacology (Berl) 236, 831-838.

Amone-P'Olak, K., Burger, H., Ormel, J., Huisman, M., Verhulst, F.C., Oldehinkel, A.J., 2009. Socioeconomic position and mental health problems in pre- and early-adolescents: the TRAILS study. Soc Psychiatry Psychiatr Epidemiol 44, 231-238.

Baggiolini, M., Clark-Lewis, I., 1992. Interleukin-8, a chemotactic and inflammatory cytokine. FEBS Lett 307, 97-101.

Banks, W.A., 2015. The blood-brain barrier in neuroimmunology: Tales of separation and assimilation. Brain Behav Immun 44, 1-8.

Beattie, E.C., Stellwagen, D., Morishita, W., Bresnahan, J.C., Ha, B.K., Von Zastrow, M., Beattie, M.S., Malenka, R.C., 2002. Control of synaptic strength by glial TNFalpha. Science 295, 2282-2285.

Becher, B., Spath, S., Goverman, J., 2017. Cytokine networks in neuroinflammation. Nat Rev Immunol 17, 49-59.

Bernardino, L., Agasse, F., Silva, B., Ferreira, R., Grade, S., Malva, J.O., 2008. Tumor necrosis factor-alpha modulates survival, proliferation, and neuronal differentiation in neonatal subventricular zone cell cultures. Stem Cells 26, 2361-2371.

Beurel, E., Lowell, J.A., 2018. Th17 cells in depression. Brain Behav Immun 69, 28-34.

Beurel, E., Lowell, J.A., Jope, R.S., 2018. Distinct characteristics of hippocampal pathogenic TH17 cells in a mouse model of depression. Brain Behav Immun 73, 180-191.

Blank, T., Detje, C.N., Spiess, A., Hagemeyer, N., Brendecke, S.M., Wolfart, J., Staszewski, O., Zoller, T., Papageorgiou, I., Schneider, J., Paricio-Montesinos, R., Eisel, U.L., Manahan-Vaughan, D., Jansen, S., Lienenklaus, S., Lu, B., Imai, Y., Muller, M., Goelz, S.E., Baker, D.P., Schwaninger, M., Kann, O., Heikenwalder, M., Kalinke, U., Prinz, M., 2016. Brain Endothelial- and Epithelial-Specific Interferon Receptor Chain 1 
Drives Virus-Induced Sickness Behavior and Cognitive Impairment. Immunity 44, 901-912.

Blondel, B., Lelong, N., Kermarrec, M., Goffinet National Coordination Group of the National Perinatal, F.S., 2012. Trends in perinatal health in France from 1995 to 2010. Results from the French National Perinatal Surveys. J Gynecol Obstet Biol Reprod (Paris) 41, e1-e15.

Bradley, K.A., Stern, E.R., Alonso, C.M., Xie, H., Kim-Schulze, S., Gabbay, V., 2019. Relationships between neural activation during a reward task and peripheral cytokine levels in youth with diverse psychiatric symptoms. Brain Behav Immun 80, 374-383.

Bradley, R.H., Caldwell, B.M., 1977. Home observation for measurement of the environment: a validation study of screening efficiency. Am J Ment Defic 81, 417-420.

Bunea, F., She, Y., Ombao, H., Gongvatana, A., Devlin, K., Cohen, R., 2011. Penalized least squares regression methods and applications to neuroimaging. Neuroimage 55, 1519-1527.

Cox, J.L., Holden, J.M., Sagovsky, R., 1987. Detection of postnatal depression. development of the 10-item Edinburgh Postnatal Depression Scale. Br J Psychiatry 150, $782-786$.

Croft, S., Stride, C., Maughan, B., Rowe, R., 2015. Validity of the strengths and difficulties questionnaire in preschool-aged children. Pediatrics 135, e1210-1219.

Cunningham, C.L., Martinez-Cerdeno, V., Noctor, S.C., 2013. Microglia regulate the number of neural precursor cells in the developing cerebral cortex. J Neurosci 33, 4216-4233.

D'Souza, S., Waldie, K.E., Peterson, E.R., Underwood, L., Morton, S.M.B., 2018. Antenatal and Postnatal Determinants of Behavioural Difficulties in Early Childhood: Evidence from Growing Up in New Zealand. Child Psychiatry Hum Dev.

Dahl, J., Ormstad, H., Aass, H.C., Malt, U.F., Bendz, L.T., Sandvik, L., Brundin, L. Andreassen, O.A., 2014. The plasma levels of various cytokines are increased during ongoing depression and are reduced to normal levels after recovery. Psychoneuroendocrinology 45, 77-86.

Dantzer, R., 2018. Neuroimmune interactions: from the brain to the immune system and vice versa. Physiol Rev 98, 477-504.

Dantzer, R., O'Connor, J.C., Freund, G.G., Johnson, R.W., Kelley, K.W., 2008. From inflammation to sickness and depression: when the immune system subjugates the brain. Nat Rev Neurosci 9, 46-56.

Davis, E.P., Pfaff, D., 2014. Sexually dimorphic responses to early adversity: implications for affective problems and autism spectrum disorder. Psychoneuroendocrinology 49, $11-25$.

de La Rochebrochard, E., Joshi, H., 2013. Siblings and child development. Longitudinal and Life Course Studies 4, 276-287.

de Winter, A.F., Oldehinkel, A.J., Veenstra, R., Brunnekreef, J.A., Verhulst, F.C., Ormel, J., 2005. Evaluation of non-response bias in mental health determinants and outcomes in a large sample of pre-adolescents. Eur J Epidemiol 20, 173-181.

Derecki, N.C., Cardani, A.N., Yang, C.H., Quinnies, K.M., Crihfield, A., Lynch, K.R., Kipnis, J., 2010. Regulation of learning and memory by meningeal immunity: a key role for IL-4. J Exp Med 207, 1067-1080.

Deshmane, S.L., Kremlev, S., Amini, S., Sawaya, B.E., 2009. Monocyte chemoattractant protein-1 (MCP-1): an overview. J Interferon Cytokine Res 29, 313-326.

Egger, H.L., Angold, A., 2006. Common emotional and behavioral disorders in preschool children: presentation, nosology, and epidemiology. J Child Psychol Psychiatry 47, 313-337.

Elberling, H., Linneberg, A., Olsen, E.M., Goodman, R., Skovgaard, A.M., 2010. The prevalence of SDQ-measured mental health problems at age 5-7 years and identification of predictors from birth to preschool age in a Danish birth cohort: the Copenhagen Child Cohort 2000. Eur Child Adolesc Psychiatry 19, 725-735.

Filiano, A.J., Gadani, S.P., Kipnis, J., 2015. Interactions of innate and adaptive immunity in brain development and function. Brain Res 1617, 18-27.

Filiano, A.J., Xu, Y., Tustison, N.J., Marsh, R.L., Baker, W., Smirnov, I., Overall, C.C., Gadani, S.P., Turner, S.D., Weng, Z., Peerzade, S.N., Chen, H., Lee, K.S., Scott, M.M., Beenhakker, M.P., Litvak, V., Kipnis, J., 2016. Unexpected role of interferon-gamma in regulating neuronal connectivity and social behaviour. Nature 535, 425-429.

Frank, M.G., Fonken, L.K., Watkins, L.R., Maier, S.F., 2019. Microglia: neuroimmunesensors of stress. Semin Cell Dev Biol 94, 176-185.

Friedman, J., Hastie, T., Tibshirani, R., 2010. Regularization paths for generalized linear models via coordinate descent. J Stat Software 33, 1-22.

Galera, C., Bernard, J.Y., van der Waerden, J., Bouvard, M.P., Lioret, S., Forhan, A., De Agostini, M., Melchior, M., Heude, B., 2015. Prenatal Caffeine Exposure and Child IQ at Age 5.5 Years: The EDEN Mother-Child. Cohort. Biological psychiatry.

Glass, W.G., Sarisky, R.T., Vecchio, A.M., 2006. Not-so-sweet sixteen: the role of IL-16 in infectious and immune-mediated inflammatory diseases. J Interferon Cytokine Res 26, 511-520.

Golan, H., Levav, T., Mendelsohn, A., Huleihel, M., 2004. Involvement of tumor necrosis factor alpha in hippocampal development and function. Cereb Cortex 14, 97-105.

Gomez-Nicola, D., Valle-Argos, B., Pallas-Bazarra, N., Nieto-Sampedro, M., 2011. Interleukin-15 regulates proliferation and self-renewal of adult neural stem cells. Mol Biol Cell 22, 1960-1970.

Goodman, R., 1997. The Strengths and Difficulties Questionnaire: a research note. J Child Psychol Psychiatry 38, 581-586.

Goodman, R., 2001. Psychometric properties of the strengths and difficulties questionnaire. J Am Acad Child Adolesc Psychiatry 40, 1337-1345.

Graham, J.W., Olchowski, A.E., Gilreath, T.D., 2007. How many imputations are really needed? Some practical clarifications of multiple imputation theory. Prev Sci 8, 206-213.
Grandjean, P., Landrigan, P.J., 2014. Neurobehavioural effects of developmental toxicity. Lancet Neurol 13, 330-338.

Gumusoglu, S.B., Stevens, H.E., 2019. Maternal inflammation and neurodevelopmental programming: a review of preclinical outcomes and implications for translational psychiatry. Biol Psychiatry 85, 107-121.

Han, Y.M., Cheung, W.K., Wong, C.K., Sze, S.L., Cheng, T.W., Yeung, M.K., Chan, A.S. 2017. Distinct cytokine and chemokine profiles in autism spectrum disorders. Front Immunol 8, 11.

Harden, L.M., du Plessis, I., Poole, S., Laburn, H.P., 2006. Interleukin-6 and leptin mediate lipopolysaccharide-induced fever and sickness behavior. Physiol Behav 89, $146-155$.

He, Y., Hsuchou, H., Wu, X., Kastin, A.J., Khan, R.S., Pistell, P.J., Wang, W.H., Feng, J., Li, Z., Guo, X., Pan, W., 2010. Interleukin-15 receptor is essential to facilitate GABA transmission and hippocampal-dependent memory. J Neurosci 30, 4725-4734.

Heikkila, K., Sacker, A., Kelly, Y., Renfrew, M.J., Quigley, M.A., 2011. Breast feeding and child behaviour in the millennium cohort study. Arch Dis Child 96, 635-642.

Heude, B., Forhan, A., Slama, R., Douhaud, L., Bedel, S., Saurel-Cubizolles, M.J., Hankard, R., Thiebaugeorges, O., De Agostini, M., Annesi-Maesano, I., Kaminski, M., Charles, M.A., 2016. Cohort Profile: The EDEN mother-child cohort on the prenatal and early postnatal determinants of child health and development. Int J Epidemiol 45, 353-363.

Holbrook, J., Lara-Reyna, S., Jarosz-Griffiths, H., McDermott, M., 2019. Tumour necrosis factor signalling in health and disease. F1000Res 8.

Hridi, S.U., Franssen, A., Jiang, H.R., Bushell, T.J., 2019. Interleukin-16 inhibits sodium channel function and GluA1 phosphorylation via CD4- and CD9-independent mechanisms to reduce hippocampal neuronal excitability and synaptic activity. Mol Cell Neurosci 95, 71-78.

Huisman, M., Oldehinkel, A.J., de Winter, A., Minderaa, R.B., de Bildt, A., Huizink, A.C., Verhulst, F.C., Ormel, J., 2008. Cohort profile: the Dutch 'TRacking Adolescents Individual Lives' Survey'; TRAILS. Int J Epidemiol 37, 1227-1235.

Iosif, R.E., Ekdahl, C.T., Ahlenius, H., Pronk, C.J., Bonde, S., Kokaia, Z., Jacobsen, S.E., Lindvall, O., 2006. Tumor necrosis factor receptor 1 is a negative regulator of progenitor proliferation in adult hippocampal neurogenesis. J Neurosci 26, 9703-9712.

Janelidze, S., Suchankova, P., Ekman, A., Erhardt, S., Sellgren, C., Samuelsson, M., Westrin, A., Minthon, L., Hansson, O., Traskman-Bendz, L., Brundin, L., 2015. Low IL8 is associated with anxiety in suicidal patients: genetic variation and decreased protein levels. Acta Psychiatr Scand 131, 269-278.

Karin, N., Razon, H., 2018. Chemokines beyond chemo-attraction: CXCL10 and its significant role in cancer and autoimmunity. Cytokine 109, 24-28.

Kong, L., Norstedt, G., Schalling, M., Gissler, M., Lavebratt, C., 2018. The risk of offspring psychiatric disorders in the setting of maternal obesity and diabetes. Pediatrics 142.

Kontopantelis, E., White, I.R., Sperrin, M., Buchan, I., 2017. Outcome-sensitive multiple imputation: a simulation study. BMC Med Res Methodol 17, 2

Kuhn, M., 2008. Caret package. Journal of Statistical Software 28.

Leeb, H., Potscher, B.M., 2006. Can one estimate the conditional distribution of postmodel-selection estimators. Ann Stat 34, 2554-2591.

Lewitus, G.M., Pribiag, H., Duseja, R., St-Hilaire, M., Stellwagen, D., 2014. An adaptive role of TNFalpha in the regulation of striatal synapses. J Neurosci 34, 6146-6155.

Liu, B., Zupan, B., Laird, E., Klein, S., Gleason, G., Bozinoski, M., Gal Toth, J., Toth, M., 2014a. Maternal hematopoietic TNF, via milk chemokines, programs hippocampal development and memory. Nat Neurosci 17, 97-105.

Liu, Q., Xin, W., He, P., Turner, D., Yin, J., Gan, Y., Shi, F.D., Wu, J., 2014b. Interleukin17 inhibits adult hippocampal neurogenesis. Sci Rep 4, 7554.

Lu, F., Petkova, E., 2014. A comparative study of variable selection methods in the context of developing psychiatric screening instruments. Stat Med 33, 401-421.

Maurer, M., von Stebut, E., 2004. Macrophage inflammatory protein-1. Int J Biochem Cell Biol 36, 1882-1886.

McGeachy, M.J., Cua, D.J., Gaffen, S.L., 2019. The IL-17 family of cytokines in health and disease. Immunity 50, 892-906.

Melchior, M., Hersi, R., van der Waerden, J., Larroque, B., Saurel-Cubizolles, M.J., Chollet, A., Galera, C., Group, E.M.-C.C.S., 2015. Maternal tobacco smoking in pregnancy and children's socio-emotional development at age 5: The EDEN motherchild birth cohort study. Eur Psychiatry 30, 562-568.

Mesquita, A.R., Correia-Neves, M., Roque, S., Castro, A.G., Vieira, P., Pedrosa, J., Palha, J.A., Sousa, N., 2008. IL-10 modulates depressive-like behavior. J Psychiatr Res 43, 89-97.

Mitchell, R.H., Goldstein, B.I., 2014. Inflammation in children and adolescents with neuropsychiatric disorders: a systematic review. J Am Acad Child Adolesc Psychiatry 53, 274-296.

Morimoto, K., Nakajima, K., 2019. Role of the immune system in the development of the central nervous system. Front Neurosci 13, 916.

Munshi, S., Parrilli, V., Rosenkranz, J.A., 2019. Peripheral anti-inflammatory cytokine Interleukin-10 treatment mitigates interleukin-1beta - induced anxiety and sickness behaviors in adult male rats. Behav Brain Res 372.

Nadeem, A., Ahmad, S.F., Al-Harbi, N.O., Fardan, A.S., El-Sherbeeny, A.M., Ibrahim, K.E., Attia, S.M., 2017. IL-17A causes depression-like symptoms via NFkappaB and p38MAPK signaling pathways in mice: Implications for psoriasis associated depression. Cytokine 97, 14-24.

Niclasen, J., Skovgaard, A.M., Andersen, A.M., Somhovd, M.J., Obel, C., 2013. A confirmatory approach to examining the factor structure of the Strengths and Difficulties Questionnaire (SDQ): a large scale cohort study. J Abnorm Child Psychol 41, 355-365.

Noonan, K., Burns, R., Violato, M., 2018. Family income, maternal psychological distress 
and child socio-emotional behaviour: Longitudinal findings from the UK Millennium Cohort Study. SSM Popul Health 4, 280-290.

Norris, G.T., Kipnis, J., 2019. Immune cells and CNS physiology: microglia and beyond. J Exp Med 216, 60-70.

O'Connor, T.G., Willoughby, M.T., Moynihan, J.A., Messing, S., Vallejo Sefair, A., Carnahan, J., Yin, X., Caserta, M.T., 2019. Early childhood risk exposures and inflammation in early adolescence. Brain Behav Immun.

Ogundele, M.O., 2018. Behavioural and emotional disorders in childhood: a brief overview for paediatricians. World J Clin Pediatr 7, 9-26.

Pan, W., Wu, X., He, Y., Hsuchou, H., Huang, E.Y., Mishra, P.K., Kastin, A.J., 2013. Brain interleukin-15 in neuroinflammation and behavior. Neurosci Biobehav Rev 37, 184-192.

Pavlou, M., Ambler, G., Seaman, S., De Iorio, M., Omar, R.Z., 2016. Review and evaluation of penalised regression methods for risk prediction in low-dimensional data with few events. Stat Med 35, 1159-1177.

Pedersen, J.M., Mortensen, E.L., Christensen, D.S., Rozing, M., Brunsgaard, H., Meincke, R.H., Petersen, G.L., Lund, R., 2018. Prenatal and early postnatal stress and later life inflammation. Psychoneuroendocrinology 88, 158-166.

Philippat, C., Heude, B., Botton, J., Alfaidy, N., Calafat, A.M., Slama, R., Group, E.M.C.C.S., 2019. Prenatal exposure to select phthalates and phenols and associations with fetal and placental weight among male births in the EDEN cohort (France). Environ Health Perspect 127, 17002.

Philippat, C. Nakiwala, D., Calafat, A.M., Botton, J., De Agostini, M., Heude, B., Slama, R., Group, E.M.-C.S., 2017. Prenatal exposure to nonpersistent endocrine disruptors and behavior in boys at 3 and 5 years. Environ Health Perspect 125.

Polanska, K., Jurewicz, J., Hanke, W., 2015. Smoking and alcohol drinking during pregnancy as the risk factors for poor child neurodevelopment - A review of epidemiological studies. Int J Occup Med Environ Health 28, 419-443.

Pollmacher, T., Haack, M., Schuld, A., Reichenberg, A., Yirmiya, R., 2002. Low levels of circulating inflammatory cytokines-do they affect human brain functions? Brain Behav Immunol 16, 525-532.

Quan, N., 2014. In-depth conversation: spectrum and kinetics of neuroimmune afferent pathways. Brain Behav Immunol 40, 1-8.

Radloff, L.S., 1977. The CES-D scale: a self-report depression scale for research in the general population. Appl Psychol Meas 1, 385-401.

Russell, G., Rodgers, L.R., Ford, T., 2013. The strengths and difficulties questionnaire as a predictor of parent-reported diagnosis of autism spectrum disorder and attention deficit hyperactivity disorder. PLoS One 8.

Russell, G., Rodgers, L.R., Ukoumunne, O.C., Ford, T., 2014. Prevalence of parent-reported ASD and ADHD in the UK: findings from the Millennium Cohort Study. J Autism Dev Disord 44, 31-40.

Saghazadeh, A., Ataeinia, B., Keynejad, K., Abdolalizadeh, A., Hirbod-Mobarakeh, A. Rezaei, N., 2019. A meta-analysis of pro-inflammatory cytokines in autism spectrum disorders: Effects of age, gender, and latitude. J Psychiatr Res 115, 90-102.

Sanchez, C.E., Barry, C., Sabhlok, A., Russell, K., Majors, A., Kollins, S.H., Fuemmeler, B.F., 2018. Maternal pre-pregnancy obesity and child neurodevelopmental outcomes: a meta-analysis. Obes Rev 19, 464-484.

Santello, M., Bezzi, P., Volterra, A., 2011. TNFalpha controls glutamatergic gliotransmission in the hippocampal dentate gyrus. Neuron 69, 988-1001.

Saraiva, M., Vieira, P., O'Garra, A., 2019. Biology and therapeutic potential of interleukin10. J Exp Med.

Schneiders, J., Drukker, M., van der Ende, J., Verhulst, F.C., van Os, J., Nicolson, N.A., 2003. Neighbourhood socioeconomic disadvantage and behavioural problems from late childhood into early adolescence. J Epidemiol Community Health 57, 699-703.

Shen, Y., Ou, J., Liu, M., Shi, L., Li, Y., Xiao, L., Dong, H., Zhang, F., Xia, K., Zhao, J. 2016. Altered plasma levels of chemokines in autism and their association with social behaviors. Psychiatry Res 244, 300-305.

Smith, S.E., Li, J., Garbett, K., Mirnics, K., Patterson, P.H., 2007. Maternal immune activation alters fetal brain development through interleukin-6. J Neurosci 27, 10695-10702.

Stellwagen, D., Malenka, R.C., 2006. Synaptic scaling mediated by glial TNF-alpha, Nature 440, 1054-1059.

Stone, L.L., Otten, R., Engels, R.C., Vermulst, A.A., Janssens, J.M., 2010. Psychometric properties of the parent and teacher versions of the strengths and difficulties questionnaire for 4- to 12-year-olds: a review. Clin Child Fam Psychol Rev 13, 254-274.

van Buuren, S., Groothuis-Oudshoorn, K., 2011. Mice: multivariate imputation by chained equations in R. J Stat Software 45, 1-67.

van der Waerden, J., Bernard, J.Y., De Agostini, M., Saurel-Cubizolles, M.J., Peyre, H., Heude, B., Melchior, M., Group, E.M.-C.C.S., 2017. Persistent maternal depressive symptoms trajectories influence children's IQ: the EDEN mother-child cohort. Depress Anxiety 34, 105-117.

van der Waerden, J., Galera, C., Larroque, B., Saurel-Cubizolles, M.J., Sutter-Dallay, A.L. Melchior, M., Group, E.M.-C.C.S., 2015. Maternal depression trajectories and children's behavior at age 5 years. J Pediatr 166 (1440-1448).

Vasquez, M.M., Hu, C., Roe, D.J., Chen, Z., Halonen, M., Guerra, S., 2016. Least absolute shrinkage and selection operator type methods for the identification of serum biomarkers of overweight and obesity: simulation and application. BMC Med Res Methodol 16, 154.

Waldmann, P., Meszaros, G., Gredler, B., Fuerst, C., Solkner, J., 2013. Evaluation of the lasso and the elastic net in genome-wide association studies. Front Genet 4, 270.

Walter, S., Tiemeier, H., 2009. Variable selection: current practice in epidemiological studies. Eur J Epidemiol 24, 733-736.

Wu, W.L., Hsiao, E.Y., Yan, Z., Mazmanian, S.K., Patterson, P.H., 2017. The placental interleukin- 6 signaling controls fetal brain development and behavior. Brain Behav Immun 62, 11-23.

Zanos, T.P., Silverman, H.A., Levy, T., Tsaava, T., Battinelli, E., Lorraine, P.W., Ashe, J.M., Chavan, S.S., Tracey, K.J., Bouton, C.E., 2018. Identification of cytokine-specific sensory neural signals by decoding murine vagus nerve activity. Proc Natl Acad Sci U S A 115, E4843-E4852.

Zupan, B., Liu, B., Taki, F., Toth, J.G., Toth, M., 2017. Maternal Brain TNF-alpha Programs Innate Fear in the Offspring. Curr Biol 27 (3859-3863). 